muscular hypotonia in two of these cases is notable. It argues against Evans's hypothesis, and prompted the suggestion put forward by Dr. P. H. Sandifer that a unitary concept is required to explain these three separately described conditions- “ benign congenital hypotonia" or amyotonia congenita, Möbius's syndrome, and flaccid bulbar palsy of muscular origin. This suggestion is supported by the evidence presented here, for not only do these 10 children commonly show facial paresis, but their motor development is significantly retarded even where hypotonia is not flagrant enough to excite comment.

None of these children walked unaided before the age of 15 months, and the average age at which this skill was achieved was 2 years 3 months. Excluding those cases where hypotonia was detectable the average age was 21 months. In the absence of any other explanation-for example, cerebral palsy, mental subnormality-it seems possible that the skeletal musculature shares or shared the same defect as the bulbar and facial musculature. With lessons learnt from recent advances in our understanding of the progressive muscular dystrophies, one looks most hopefully to histochemical methods to elucidate the nature of this defect. The fact that this hypothetical defect reveals itself in so many different sites need not encourage speculation about possible multiple pathology, for the same capriciousness can be seen in other maladies (such as myasthenia gravis) which are recognized to be caused by single pathology.

\section{Summary}

The cases of 10 children with congenital, non-progressive, flaccid bulbar palsy, at first producing feeding difficulties with regurgitation of fluids, and later disturbances of articulation, are described. The prognosis of the condition is benign if respiratory complications do not occur, but the child may be left with a permanent dysarthria. The children have normal intelligence, but their gross motor development (as assessed by the age at which they first walked unaided) is considerably retarded. The condition was associated with facial diplegia (Möbius's syndrome) in seven of the cases, and with benign congenital hypotonia in two of them. The presence of a single defect responsible for all three associated conditions is postulated.

I should like to express my gratitude to Dr. P. H. Sandifer for the help and encouragement he has given me in the writing of this paper. Sir Wilfrid Sheldon kindly gave permission to publish details of the first case, which was under his care.

\section{REFERENCES}

Benson, P. F. (1962). Proc, roy. Soc. Med., 55, 237.

Benson, P. F. (1965). Arch. Dis. Childh., 30, 237.

Evans, P. R. (1955). Arch. Dis. Childh.,

Ingram, T. T. S. (1959). Arch. Dis. Childh., 34, 444

Möbius, P. J. (1892). Münch. med. Wschr., 39, 17.

\title{
Clinical ard Therapeutic Aspects of Kerosene Poisoning: A Series of 200 Cases
}

\author{
B. J. BALDACHIN,* M.R.C.P.ED., D.C.H. ; R. N. MELMED,* M.B., CH.B.
}

Brit. med. F., 1964, 2, 28-30

Ingestion of kerosene is the commonest form of accidental poisoning encountered in African patients in Bulawayo. Of 42 cases of accidental poisoning admitted to Mpilo Central Hospital during the first nine months of 1963,32 were due to the effects of kerosene ingestion-an incidence of approximately $75 \%$. This trend had been apparent in previous years, and from August 1958 until August 1963200 cases of kerosene ingestion have been admitted. This condition has been reported to occur frequently in other centres in Southern Africa (Kossick, 1961 ; McDonald, 1961). Kerosene is widely used for lighting, cooking, and heating purposes in the African townships of Bulawayo. Ingestion usually occurs in young children as a result of the ready availability of kerosene stored in various household utensils, such as cups, tins, and bottles.

The main controversy in the management of these cases is related to the place of gastric lavage in treatment (B.M.F., 1963). The present study has been undertaken to assist in the assessment of this aspect.

\section{Present Investigation}

The 200 cases of kerosene poisoning admitted over a period of five years form the subject of this investigation.

Age Distribution.-The average age was 19 months, the majority falling within the range of 5 months to 5 years. The series included three adults, aged 20,27 , and 40 years, who had

* Department of Medicine, Mpilo Central Hospital, Bulawayo, Southern Rhodesia. drunk relatively large quantities of kerosene in attempts at suicide.

The monthly incidence of kerosene poisoning showed a definite seasonal variation over the five-year period. The numbers were uniformly high during summer (September to April), but there was a sharp decline during the winter months (May to August).

\section{Clinical Features}

Although histories were not reliable, particularly with regard to the quantity consumed, a story of ingestion of kerosene was usually obtained from the parents.

The signs and symptoms could be divided into three distinct categories:

1. Constitutional Disturbance.-Moderate pyrexia $\left(99-103^{\circ} \mathrm{F}\right.$ $\left(37.2-39.4^{\circ}\right.$ C.) ) occurred in 95 cases, usually within 24 hours of ingestion. In some cases this was the only abnormality noted, without any clinical or radiological evidence of involvement of a specific system. The duration of pyrexia varied considerably, and bore no apparent relation to the severity of the illness. An illustrative case was that of a child aged $2 \frac{1}{2}$ years, who had a temperature of $104.5^{\circ} \mathrm{F}$. $\left(40.3^{\circ}\right.$ C. $)$ on admission, and who was discharged well after 48 hours. There was no evidence of pulmonary involvement. Drowsiness was a prominent feature in a number of cases.

2. Gastro-intestinal Involvement.-A story of vomiting was frequently obtained, but the exact. incidence could not be ascertained, owing to the inaccuracy of the history in many cases. Diarrhoea was uncommon, occurring in only six cases. 
3. Respiratory Involvement.-The following features, suggesting involvement of the respiratory tract, were recorded: cough, tachypnoea, rhonchi (localized or generalized), and crepitations at the lung bases. In 71 cases, or approximately $35 \%$ of the total, one or more of these signs were present. The severest cases of respiratory involvement presented a characteristic picture of lethargy, tachycardia, tachypnoea, cyanosis, and scattered crepitations or rhonchi, especially at the lung bases. These signs may manifest within one or two hours after ingestion of kerosene. Frank pulmonary oedema may supervene, and was seen in the one fatal case in this series (see below).

\section{Radiological Aspects}

Routine chest $x$-ray films were not taken of all cases admitted during the period of the survey. However, in 30 consecutive unselected cases $x$-rayed during 1962 radiological abnormalities were demonstrated in $26(87 \%)$. The changes resembled those of non-segmental consolidation and/or atelectasis entirely confined to the middle and lower zones of both lungs. In 16 of the 26 cases the changes were bilateral. This bilateral distribution has been noted to be characteristic of the condition (Caffey, 1961). There seemed to be no close correlation between clinical signs of pulmonary involvement and the presence or absence of radiological change. Among the 26 cases showing $x$-ray changes mentioned above, there were seven with no auscultatory evidence of pulmonary involvement.

\section{Treatment}

A standard regime of treatment was instituted for all cases of kerosene poisoning admitted to this hospital during the period of this survey. All the patients were admitted to hospital for observation, and were given 250,000 units of crystalline penicillin six-hourly for five days. In those who were discharged in less than five days the course was completed by daily injections of procaine penicillin. The penicillin course was given without regard to the presence of clinical or radiological signs. In no case was gastric lavage employed. The presence of cyanosis was regarded as a specific indication for administration of oxygen.

\section{Morbidity and Mortality}

In $134(67 \%)$ of the patients one or more of the clinical or radiological signs listed above were manifested. There was only one fatal case. This patient was a 2-year-old child weighing $30 \mathrm{lb}$. (13.6 kg.), who ingested an unknown quantity of kerosene approximately two and a half hours before admission. On initial examination he was severely cyanosed, and showed considerable respiratory distress. In spite of treatment with oxygen, antibiotics, and cortisone, he died one and a half hours later. Necropsy showed severe pulmonary oedema.

\section{Discussion}

Kerosene, a product of crude oil, is a hydrocarbon complex with high boiling-point and low surface-tension. According to Deichmann et al. (1944) the toxicity of different brands of kerosene may vary with the source of the crude oil from which it is refined. Our inquiries show that locally available kerosene is produced almost entirely from Middle East crude oil.

Spector (1956) classed kerosene as relatively harmless via the oral route, as the oral $\mathrm{LD}_{50}$ is stated to be $15 \mathrm{~g}$. $/ \mathrm{kg}$. body weight or greater. On the basis of experimental work conducted on dogs, Richardson and Pratt-Thomas (1951) concluded that a $50-\mathrm{lb}$. $(22.7-\mathrm{kg}$.) child would have to ingest more than a pint
$(570 \mathrm{ml}$ ) $)$ of kerosene to develop a fatal pneumonitis. These authors eliminated regurgitation and aspiration by ligating the cardia and instilling kerosene direct into the stomach. It is well known that toxicity of a substance depends on its portal of entry. Gerarde (1959) stated that the ratio of the oral to intratracheal $\mathrm{LD}_{50}$ of kerosene is approximately $140: 1$. By a series of experiments in rats, rabbits, and chickens, he showed that large doses of kerosene could be administered by gastric intubation, subcutaneously, and intraperitoneally without the development of pulmonary injury. Conversely, the instillation of minute quantities (a fraction of a millilitre) of kerosene into the trachea or its aspiration from the mouth into the lungs of rats caused pulmonary oedema and haemorrhage, with death in a few minutes. It was shown that intravenous injection of kerosene resulted in pulmonary damage, the severity of which depended on the rapidity of injection. Pulmonary damage resulting from intravenous injection showed uniform distribution through both lungs.

Kerosene is easily aspirated when present in vomitus owing to its low surface-tension, which facilitates rapid spread over the surface of contact. This property is particularly dangerous in young children, who form the bulk of patients in all reported series, because of the relatively smaller surface area of the tracheobronchial tree.

The clinical and radiological features seen in the present series of cases clearly indicate that aspiration of kerosene is the primary cause of the pulmonary condition. This view is supported by the following facts: (a) Radiological changes were limited to the dependent portions of the lungs-i.e., the middle and lower lobes. (b) The predominating auscultatory signs were found at the lung bases. In addition, the early appearance of radiological changes, not infrequently in the absence of clinical signs, suggests the rapid spread of kerosene by direct contact with the respiratory mucosa, and by posture. Although Gerarde (1959) has shown that pulmonary damage does result from haematogenous carriage of kerosene to the lungs, this occurred only as the result of rapid intravenous injection, but not following gastro-intestinal absorption. The distribution of the lesions after intravenous injection was uniform through both lungs. This contrasts with the dependent distribution of the lesions found almost invariably in clinical cases of kerosene ingestion.

In a number of cases pyrexia and/or drowsiness appeared to be the direct result of kerosene absorption, in the absence of respiratory involvement. Although these symptoms suggest pyrogenic and narcotic actions by kerosene, they were never severe enough to give rise to concern. In the three cases of suicidal attempts seen, in which the subjects presumably ingested large quantities of kerosene, constitutional disturbance was minimal.

The experimental evidence quoted, together with our clinical experience, indicates that gastric lavage should have no place in the treatment of accidental kerosene ingestion. As most cases of accidental ingestion occur in infants and young children, the induction of vomiting by attempting gastric lavage will almost inevitably be associated with some aspiration of kerosene into the lungs. Where it appears probable that large quantities of kerosene have been ingested, absorption from the gastrointestinal tract may be delayed by the administration of olive oil. Gerarde has shown experimentally that olive oil delays the absorption of kerosene into the blood from the gastro-intestinal tract, whereas mineral oil has the opposite effect.

The low mortality rate in the present series $(0.5 \%)$ emphasizes that kerosene is relatively non-toxic by the oral route, and affirms the efficacy of conservative supportive measures, together with prophylactic antibiotic therapy.

The possible value of steroid therapy has not been fully assessed, but it has been suggested that this may be beneficial in certain circumstances (Mayock et al., 1961). 


\section{Summary}

A series of 200 cases of kerosene ingestion is reviewed.

Clinical and radiological findings suggest that the most significant complication is pulmonary damage following aspiration. Systemic effects of kerosene absorption appeared to be of little practical importance.

A standard conservative regime of prophylactic penicillin, without gastric lavage, was employed. The mortality rate was $0.5 \%$.

A review of experimental reports and clinical findings indicate that treatment should be conservative, and that gastric lavage is contraindicated in the management of this condition.

We should like to express our thanks to Dr. P. E. S. Palmer, senior radiologist, Mpilo Hospital, for the $x$-ray report ; and to
Dr. M. Webster, Secretary for Health, Southern Rhodesia, for permission to publish.

\section{REFERENCES}

Brit. med. 7., 1963, 1, 208.

Caffey, J. P. (1961). Paediatric X-ray Diagnosis, 4th ed., p. 322. Year Book Medical Publishers, Chicago.

Deichmann, W. B., Kitzmiller, K. V., Witherup, B. S., and Johansmann, R. (1944). Ann. intern. Med., 21, 803.

Gerarde, H. W. (1959). Toxicol. appl. Pharmacol., 1, 462.

Kossick, P. (1951). S. Afr. med. 7., 35, 112.

Mayock, R. L., Bozorgnia, N., and Zinsser, H. F. (1961). Ann. intern. Med., 54, 559.

McDonald, R. (1961). S. Afr. med. f., 35, 21.

Richardson. J. A., and Pratt-Thomas, H. R. (1951). Amer. F. med. Sci., 221, 531 .

Spector, W. S. (1956). Handbook of Toxicology, vol. 1, “Acute Toxicities." Saunders, Philadelphia. Quoted by Gerarde (1959).

\title{
Cervical Phimosis
}

\author{
PREMA M. NAIDU,* M.D., F.R.C.S.ED., F.R.C.o.G.; SUVARNA RAMASWAMY, $\dagger$ M.D. \\ SUNDARI KRISHNA, $\ddagger$ M.D.
}

Brit. med. F., 1964, 2, 30-31

The developmental origin of any transverse occluding membrane in the vagina is a much-disputed subject. Rubin (1944) first used the term " cervical phimosis" to describe a condition of a transverse vaginal septum situated immediately below the cervix. This septum has a small opening through which menstruation occurs and conception, occasionally, takes place. In a typical example of this congenital abnormality there is an annular fold of vaginal wall which appears to cover the entire cervix during rest but would retract when the cervix is pulled upon, as in Case 4 below.

\section{Case Reports}

Four cases with congenital transverse septa of the cervical phimosis type were met with in this hospital during a sixmonths period from September, 1960.

Case 1.-The patient, aged 19, was admitted to hospital in September 1960 with a history of dysmenorrhoea since her menarche five years previously. Her menstrual cycles were regular. She had been married for three years. She was a normally developed young woman of average build. Pelvic examination revealed a transverse septum in the upper part of the vagina immediately below the cervix. There was a small opening in the septum a little to the left side admitting a probe. On rectal examination the uterus was felt; it was normal in size. A diagnosis of cervical phimosis was obvious. Incisions were made on each side of the septum starting from the central opening. This resulted in bilateral wing-shaped raw areas, which were closed with interrupted linen sutures. The result was satisfactory.

Case 2.-This patient, aged 25, was admitted in November 1960 with a history of four months' amenorrhoea. Her menstrual cycles had been regular. Caesarean section had been performed elsewhere six years previously, presumably for non-dilatation of the cervix. Vaginal examination revealed a transverse septum in the upper part

* Professor of Obstetrics and Gynaecology, Institute of Obstetrics and Gynaecology, Government Maternity Hospital, Hyderabad, India.

t Assistant Professor, Institute of Obstetrics and Gynaecology, Government Maternity Hospital, Hyderabad, India.

‡ Gynaecological Registrar, Institute of Obstetrics and Gynaecology, Government Maternity Hospital, Hyderabad, India. of the vagina about $1 \mathrm{~cm}$. below the cervix with a small opening almost in its centre. This septum was treated by lateral incisions as in Case 1. The patient became pregnant again and delivered spontaneously. No septum could be palpated or delineated in the post-natal period.

Case 3.-A primigravida, aged 22, was seen in labour in December 1960. During the course of a vaginal examination a transverse septum at the upper third of the vagina was noted. There was a central opening admitting a finger, and the foetal head was stretching the septum. Transverse incision of the septum was followed by spontaneous delivery of a live term infant. At a follow-up examination a year later a cicatricial ring was noted about $2 \mathrm{~cm}$. below the cervix. No definitive treatment was carried out.

Case 4.- The patient, aged 28, was admitted on 4 March 1961 for investigation of infertility. Her periods had been regular, but she gave a history of dysmenorrhoea of the spasmodic type. She had failed to conceive even after ten years of married life. On examination the vagina was found to be of normal depth. The uterus was retroverted and normal in size. There was a fleshy annular septum in the upper third of the vagina which behaved like the shutter of a camera when traction was applied on to the cervix (see Fig.). Treatment was not thought necessary.

\section{Discussion}

A complete atresia or a transverse occluding membrane at the lower levels of the vagina resulting in cryptomenorrhoea is seen fairly often; but the condition of a transverse incomplete septum, with a small opening, situated across the upper vagina and aptly known as "phimosis of the cervix" is less common. This condition is likely to be mistaken for congenital absence of cervix and uterus with a normal vaginal vault as indicated by Jeffcoate (1957). Minor degrees of this deformity appearing as an annular constriction of the upper vagina may be recognized more often if this condition is kept in mind when cases of infertility or dyspareunia are being examined.

It is now widely accepted that the upper four-fifths of the vagina is developed from the Müllerian ducts and the lower one-fifth from the sino-vaginal bulbs. Certain anomalies at the lower levels of the vagina support this composite origin 